Check for updates

Cite this: RSC Adv., 2019, 9, 17382

Received 13th February 2019

Accepted 27th May 2019

DOI: 10.1039/c9ra01136f

rsc.li/rsc-advances

\section{Theoretical study on the electronic structure and second-order nonlinear optical properties of benzannulated or selenophene-annulated expanded helicenes $\dagger$}

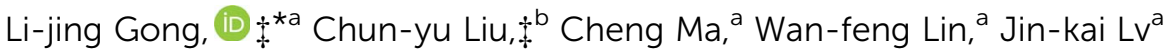 \\ and Xiang-yu Zhang ${ }^{\text {a }}$
}

Currently, discovering new materials with superior second-order nonlinear optical (NLO) performance has become a very hot research topic in the fields of chemistry and materials science. Now, density functional theory (DFT) has become a powerful tool to predict the performance of novel materials. In this paper, based on benzannulated and selenophene-annulated expanded helicenes, twenty-six helicenes are designed by introduction donor/acceptor moieties and their combinations at different substituent positions. The geometrical/electronic structures, electronic transition, and second-order NLO properties of these helicenes are full investigated by DFT/TDDFT theory. The investigations show that these helicenes have large first hyperpolarizability values ( $\left.\beta_{\mathrm{HRS}}\right)$. For instance, the $\beta_{\mathrm{HRS}}$ value $\left(29.95 \times 10^{-30}\right.$ esu) of helicene $\mathrm{H} 24$ is about 7 times larger than that of the highly $\pi$-delocalized phenyliminomethyl ferrocene complex. In addition, the introduction of acceptor $\mathrm{NO}_{2}$ unit at $\mathrm{R}_{7}$ and $\mathrm{R}_{8}$ positions for helicenes $\mathrm{H} 1$ and $\mathrm{H} 15$ can obtain the largest $\beta_{\mathrm{HRS}}$ value, which is attributed to the enhancement of electron acceptor ability. In view of large NLO response and intrinsic asymmetric structures, the studied helicenes have the possibility to be excellent second-order NLO materials.

\section{Introduction}

Helicenes have been defined as polycyclic aromatic hydrocarbons with nonplanar screw-shaped structures formed by orthofused benzene or other aromatic rings. These helicenes possess many fascinating properties because of their helical molecular geometries, such as large nonlinear optical responses, chiroptical, circular polarized absorption and emission, and relatively high solubility. ${ }^{1-7}$ Therefore, they are now sparking extensive attention in the areas of electronics and optoelectronics, nonlinear optics, switches and molecular recognition. ${ }^{8-14}$

\footnotetext{
${ }^{a}$ Aviation University of Air Force, Changchun, 130022 Jilin, China. E-mail: gonglijing@ 126.com

${ }^{b}$ Institute of Functional Material Chemistry, National \& Local United Engineering Lab for Power Battery, Faculty of Chemistry, Northeast Normal University, Changchun, 130024 Jilin, China

$\dagger$ Electronic supplementary information (ESI) available: The selected bond lengths for helicene $\mathbf{H 1}$ between experiment and calculation, the contour plots of the HOMO and LUMO for the studied helicenes H2-H4, H6-H9, H11, H16-H18 and H20-H23, and H25, the computed main energy absorption band $(\lambda, \mathrm{nm})$ at the different basis sets level for helicene $\mathbf{H 1}$, the computed main energy absorption band $(\lambda, \mathrm{nm})$ using the different functionals for helicene $\mathbf{H 1}$, the electron density difference maps of helicenes $\mathbf{H 2}-\mathbf{H}$ 9, H11-H14, H16-H23 and $\mathbf{H 2 5}-\mathbf{H} 28$, and the calculated $\beta_{\mathrm{HRS}}$ values $\left(\times 10^{-30} \mathrm{esu}\right)$ of helicenes H1-H28 by using four DFT functionals are shown. See DOI: 10.1039/c9ra01136f

\$ These authors contributed equally.
}

In general, the currently studied helicenes can be divided into three types from the perspective of the fused rings arrangement. One type only contains angularly fused rings. The second is the combinations of angular with linear fusion of benzene rings, are viewed as expanded helicenes. The third is laterally $\pi$-extended helicenes based on the first type. The latter two types may lead to novel electronic, photophysical and chiroptical properties due to the size increase of a helicene. ${ }^{15}$

A large number of laterally extended helicenes have been well-characterized. ${ }^{16-19}$ For example, Collins et al. reported that pyrene and [4]- or [5] helicene with an increased $\pi$ surface displayed significant red-shifts compared to the parent [5] helicene in both the UV/Vis and the fluorescence spectra, and adopts coplanar or stacked arrangements in the solid state. ${ }^{20}$ The pyrenebased dibenzo[7]helicene and 2H-pyran[7]helicene lateral derivatives with the fluorescent quantum yields in dichloromethane of $\mathrm{FF}=0.10$ and 0.17 have been reported. ${ }^{21}$ They form remarkably stabilised intramolecular excimer states upon excitation and exhibit large Stokes shifts respectively. Nuckolls et $a .^{22}$ demonstrated that perylenediimide (PDI)-based $\pi$ extended helicenes results in the collision of $\pi$-electron clouds between two PDI subunits, which enhance the delocalization of electrons. However, the studies of expanded helicenes are very few, especially the study on the modification of their structure. 
Recently, Tilley et $a .^{23}$ reported a benzannulated or selenophene-annulated expanded helicenes, which is named helicenes $\mathbf{H 1}$ and $\mathbf{H 1 5}$, respectively (Fig. 1). They are composed of alternating linearly and angularly fused rings and contain larger $\pi$-systems than typical helicenes, and possess an internal cavity. The $\mathbf{H 1}$ forms dimeric structure in the solid state, and no $\pi$-stacking interactions between dimers, while helicene $\mathbf{H 1 5}$ exhibits long-range $\pi$-stacking in the solid state. These properties may result in a certain application in the field of organic electronics. Moreover, their unique helical structure arising from the chirality can meet the basic requirement of secondorder NLO material. Accordingly, helicenes H1 and H15 are likely to be the potential second-order NLO material.

It is well known that macroscopic properties strongly related to microcosmic electron structures, especially for electronic transition properties upon excitation. By all appearances, it is necessary to systemically investigate the photophysical properties and establish structure-property relationships at the quantum chemistry level of theory, so that their performance further improve. To achieve this purpose, twenty-six benzannulated or selenophene-annulated expanded helicenes H2-H14 and H16-H28 were designed. The introduction of donor $\mathrm{NH}_{2}$ unit or acceptor $\mathrm{NO}_{2}$ unit at $\mathrm{R}_{1}$ and $\mathrm{R}_{2}$, or $\mathrm{R}_{3}$ and $\mathrm{R}_{4}$, or $\mathrm{R}_{5}$ and

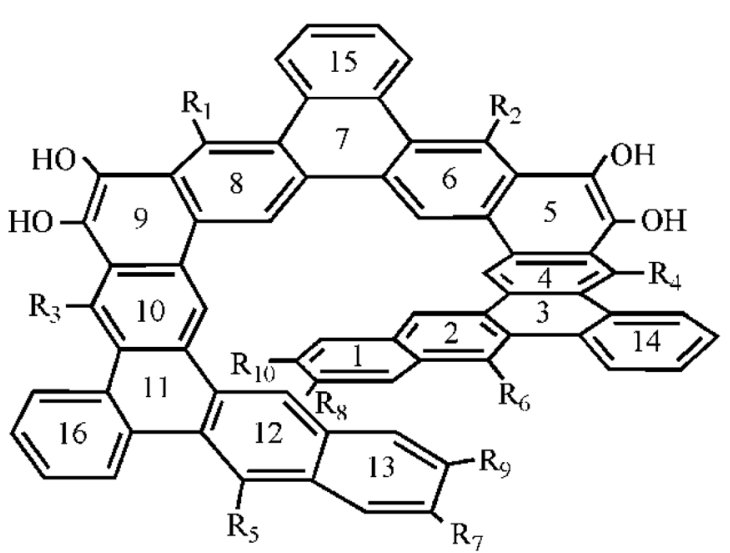

$$
\begin{array}{ll}
\text { H1: } \mathrm{R}_{1}=\mathrm{R}_{2}=\mathrm{R}_{3}=\mathrm{R}_{4}=\mathrm{R}_{5}=\mathrm{R}_{6}=\mathrm{R}_{7}=\mathrm{R}_{8}=\mathrm{R}_{9}=\mathrm{R}_{10}=\mathrm{H} \\
\text { H2: } \mathrm{R}_{1}=\mathrm{R}_{2}=\mathrm{NH}_{2} & \mathrm{R}_{3}=\mathrm{R}_{4}=\mathrm{R}_{5}=\mathrm{R}_{6}=\mathrm{R}_{7}=\mathrm{R}_{8}=\mathrm{R}_{9}=\mathrm{R}_{10}=\mathrm{H} \\
\text { H3: } \mathrm{R}_{3}=\mathrm{R}_{4}=\mathrm{NH}_{2} & \mathrm{R}_{1}=\mathrm{R}_{2}=\mathrm{R}_{5}=\mathrm{R}_{6}=\mathrm{R}_{7}=\mathrm{R}_{8}=\mathrm{R}_{9}=\mathrm{R}_{10}=\mathrm{H} \\
\text { H4: } \mathrm{R}_{5}=\mathrm{R}_{6}=\mathrm{NH}_{2} & \mathrm{R}_{1}=\mathrm{R}_{2}=\mathrm{R}_{3}=\mathrm{R}_{4}=\mathrm{R}_{7}=\mathrm{R}_{8}=\mathrm{R}_{9}=\mathrm{R}_{10}=\mathrm{H} \\
\text { H5: } \mathrm{R}_{7}=\mathrm{R}_{8}=\mathrm{NH}_{2} & \mathrm{R}_{1}=\mathrm{R}_{2}=\mathrm{R}_{3}=\mathrm{R}_{4}=\mathrm{R}_{5}=\mathrm{R}_{6}=\mathrm{R}_{9}=\mathrm{R}_{10}=\mathrm{H} \\
\text { H6: } \mathrm{R}_{9}=\mathrm{R}_{10}=\mathrm{NH}_{2} & \mathrm{R}_{1}=\mathrm{R}_{2}=\mathrm{R}_{3}=\mathrm{R}_{4}=\mathrm{R}_{5}=\mathrm{R}_{6}=\mathrm{R}_{7}=\mathrm{R}_{8}=\mathrm{H} \\
\text { H7: } \mathrm{R}_{1}=\mathrm{R}_{2}=\mathrm{NO}_{2} & \mathrm{R}_{3}=\mathrm{R}_{4}=\mathrm{R}_{5}=\mathrm{R}_{6}=\mathrm{R}_{7}=\mathrm{R}_{8}=\mathrm{R}_{9}=\mathrm{R}_{10}=\mathrm{H} \\
\text { H8: } \mathrm{R}_{3}=\mathrm{R}_{4}=\mathrm{NO}_{2} & \mathrm{R}_{1}=\mathrm{R}_{2}=\mathrm{R}_{5}=\mathrm{R}_{6}=\mathrm{R}_{7}=\mathrm{R}_{8}=\mathrm{R}_{9}=\mathrm{R}_{10}=\mathrm{H} \\
\text { H9: } \mathrm{R}_{5}=\mathrm{R}_{6}=\mathrm{NO}_{2} & \mathrm{R}_{1}=\mathrm{R}_{2}=\mathrm{R}_{3}=\mathrm{R}_{4}=\mathrm{R}_{7}=\mathrm{R}_{8}=\mathrm{R}_{9}=\mathrm{R}_{10}=\mathrm{H} \\
\text { H10: } \mathrm{R}_{7}=\mathrm{R}_{8}=\mathrm{NO}_{2} & \mathrm{R}_{1}=\mathrm{R}_{2}=\mathrm{R}_{3}=\mathrm{R}_{4}=\mathrm{R}_{5}=\mathrm{R}_{6}=\mathrm{R}_{9}=\mathrm{R}_{10}=\mathrm{H} \\
\text { H11: } \mathrm{R}_{9}=\mathrm{R}_{10}=\mathrm{NO}_{2} & \mathrm{R}_{1}=\mathrm{R}_{2}=\mathrm{R}_{3}=\mathrm{R}_{4}=\mathrm{R}_{5}=\mathrm{R}_{6}=\mathrm{R}_{7}=\mathrm{R}_{8}=\mathrm{H} \\
\text { H12: } \mathrm{R}_{1}=\mathrm{R}_{2}=\mathrm{R}_{3}=\mathrm{R}_{4}=\mathrm{R}_{5}=\mathrm{R}_{6}=\mathrm{R}_{7}=\mathrm{R}_{8}=\mathrm{R}_{9}=\mathrm{R}_{10}=\mathrm{NH}_{2} \\
\text { H13: } \mathrm{R}_{1}=\mathrm{R}_{2}=\mathrm{R}_{3}=\mathrm{R}_{4}=\mathrm{R}_{5}=\mathrm{R}_{6}=\mathrm{R}_{7}=\mathrm{R}_{8}=\mathrm{R}_{9}=\mathrm{R}_{10}=\mathrm{NO}_{2} \\
\text { H14: } \mathrm{R}_{1}=\mathrm{R}_{3}=\mathrm{R}_{5}=\mathrm{R}_{7}=\mathrm{R}_{9}=\mathrm{NO}_{2} & \mathrm{R}_{2}=\mathrm{R}_{4}=\mathrm{R}_{6}=\mathrm{R}_{8}=\mathrm{R}_{10}=\mathrm{NH}_{2}
\end{array}
$$

$\mathrm{R}_{6}$, or $\mathrm{R}_{7}$ and $\mathrm{R}_{8}$, or $\mathrm{R}_{9}$ and $\mathrm{R}_{10}$ positions was named as helicenes H2-H11 and H16-H25, respectively. Helicenes H12, H13, H26, $\mathbf{H 2 7}$ are the simultaneously introduction of donor $\mathrm{NH}_{2}$ unit or acceptor $\mathrm{NO}_{2}$ unit at $\mathrm{R}_{1}-\mathrm{R}_{10}$ positions. For helicenes $\mathrm{H14}$ and H28, $N_{2}$ unit is at $R_{1}, R_{3}, R_{5}, R_{7}$ and $R_{9}$ positions, and $N_{2}$ unit is at $R_{2}, R_{4}, R_{6}, R_{8}$ and $R_{10}$ positions. In order to more clearly describe the structure and charge transfer properties, we numbered the benzene ring in the helicenes, as shown in Fig. 1. In this paper, our main goal is to shed light with the help of DFT/TDDFT calculations to (i) investigate the frontier molecular orbitals (FMOs) (ii) analyze electronic transition mechanism and (iii) study NLO properties.

\section{Computational details}

All quantum chemistry calculations were carried out with Gaussian 09 Software. ${ }^{24}$ The ground-state geometries of the studied helicenes were optimized using the $\mathrm{B}^{2} \mathrm{LYP}^{25}$ functional. The B3LYP functional is a combination of Becke's threeparameter hybrid exchange functional ${ }^{26}$ and the Lee-YangParr $^{27}$ correlation functional. Basis sets of the effective core potential (ECP) double- $\zeta$ (DZ) LANL2DZ containing relativistic effects for Se and 6-31G(d) for $\mathrm{O}, \mathrm{N}, \mathrm{C}$ and $\mathrm{H}$ atoms were

Fig. 1 Chemical structures of the studied helicenes $\mathrm{H} 1-\mathrm{H} 28$

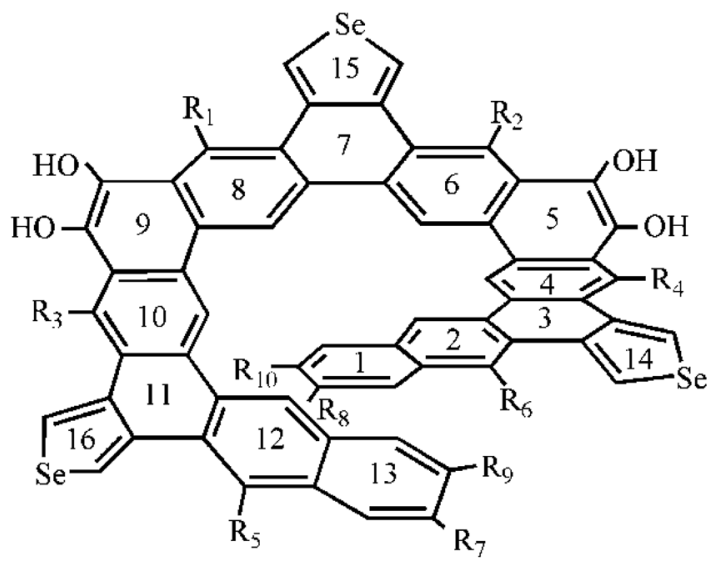

H15: $\mathrm{R}_{1}=\mathrm{R}_{2}=\mathrm{R}_{3}=\mathrm{R}_{4}=\mathrm{R}_{5}=\mathrm{R}_{6}=\mathrm{R}_{7}=\mathrm{R}_{8}=\mathrm{R}_{7}=\mathrm{R}_{10}=\mathrm{H}$

H16: $\mathrm{R}_{1}=\mathrm{R}_{2}=\mathrm{NH}_{2} \quad \mathrm{R}_{3}=\mathrm{R}_{4}=\mathrm{R}_{5}=\mathrm{R}_{6}=\mathrm{R}_{7}=\mathrm{R}_{8}=\mathrm{R}_{9}=\mathrm{R}_{10}=\mathrm{H}$

H17: $\mathrm{R}_{3}=\mathrm{R}_{4}=\mathrm{NH}_{2} \quad \mathrm{R}_{1}=\mathrm{R}_{2}=\mathrm{R}_{5}=\mathrm{R}_{6}=\mathrm{R}_{7}=\mathrm{R}_{8}=\mathrm{R}_{9}=\mathrm{R}_{10}=\mathrm{H}$

H18: $\mathrm{R}_{5}=\mathrm{R}_{6}=\mathrm{NH}_{2} \quad \mathrm{R}_{1}=\mathrm{R}_{2}=\mathrm{R}_{3}=\mathrm{R}_{4}=\mathrm{R}_{7}=\mathrm{R}_{8}=\mathrm{R}_{9}=\mathrm{R}_{10}=\mathrm{H}$

H19: $\mathrm{R}_{7}=\mathrm{R}_{8}=\mathrm{NH}_{2} \quad \mathrm{R}_{1}=\mathrm{R}_{2}=\mathrm{R}_{3}=\mathrm{R}_{4}=\mathrm{R}_{5}=\mathrm{R}_{6}=\mathrm{R}_{9}=\mathrm{R}_{10}=\mathrm{H}$

H20: $\mathrm{R}_{9}=\mathrm{R}_{10}=\mathrm{NH}_{2} \quad \mathrm{R}_{1}=\mathrm{R}_{2}=\mathrm{R}_{3}=\mathrm{R}_{4}=\mathrm{R}_{5}=\mathrm{R}_{6}=\mathrm{R}_{7}=\mathrm{R}_{8}=\mathrm{H}$

H21: $\mathrm{R}_{1}=\mathrm{R}_{2}=\mathrm{NO}_{2} \quad \mathrm{R}_{3}=\mathrm{R}_{4}=\mathrm{R}_{5}=\mathrm{R}_{6}=\mathrm{R}_{7}=\mathrm{R}_{8}=\mathrm{R}_{\mathrm{v}}=\mathrm{R}_{10}=\mathrm{H}$

H22: $\mathrm{R}_{3}=\mathrm{R}_{4}=\mathrm{NO}_{2} \quad \mathrm{R}_{1}=\mathrm{R}_{2}=\mathrm{R}_{5}=\mathrm{R}_{6}=\mathrm{R}_{7}=\mathrm{R}_{8}=\mathrm{R}_{9}=\mathrm{R}_{10}=\mathrm{H}$

H23: $\mathrm{R}_{5}=\mathrm{R}_{6}=\mathrm{NO}_{2} \quad \mathrm{R}_{1}=\mathrm{R}_{2}=\mathrm{R}_{3}=\mathrm{R}_{4}=\mathrm{R}_{7}=\mathrm{R}_{8}=\mathrm{R}_{9}=\mathrm{R}_{10}=\mathrm{H}$

H24: $\mathrm{R}_{7}=\mathrm{R}_{8}=\mathrm{NO}_{2} \quad \mathrm{R}_{1}=\mathrm{R}_{2}=\mathrm{R}_{3}=\mathrm{R}_{4}=\mathrm{R}_{5}=\mathrm{R}_{6}=\mathrm{R}_{9}=\mathrm{R}_{10}=\mathrm{H}$

H25: $\mathrm{R}_{9}=\mathrm{R}_{10}=\mathrm{NO}_{2} \quad \mathrm{R}_{1}=\mathrm{R}_{2}=\mathrm{R}_{3}=\mathrm{R}_{4}=\mathrm{R}_{5}=\mathrm{R}_{6}=\mathrm{R}_{7}=\mathrm{R}_{8}=\mathrm{H}$

H26: $\mathrm{R}_{1}=\mathrm{R}_{2}=\mathrm{R}_{3}=\mathrm{R}_{4}=\mathrm{R}_{5}=\mathrm{R}_{6}=\mathrm{R}_{7}=\mathrm{R}_{8}=\mathrm{R}_{9}=\mathrm{R}_{10}=\mathrm{NH}_{2}$

H27: $\mathrm{R}_{1}=\mathrm{R}_{2}=\mathrm{R}_{3}=\mathrm{R}_{4}=\mathrm{R}_{5}=\mathrm{R}_{6}=\mathrm{R}_{7}=\mathrm{R}_{8}=\mathrm{R}_{9}=\mathrm{R}_{10}=\mathrm{NO}_{2}$

H28: $\mathrm{R}_{1}=\mathrm{R}_{3}=\mathrm{R}_{5}=\mathrm{R}_{7}=\mathrm{R}_{9}=\mathrm{NO}_{2} \quad \mathrm{R}_{2}=\mathrm{R}_{4}=\mathrm{R}_{6}=\mathrm{R}_{8}=\mathrm{R}_{10}=\mathrm{NH}_{2}$ 
employed. Harmonic vibration frequency calculations were used to ensure the optimized structure is the most stable configuration. During the optimization process, there are no symmetry or internal coordination constraints.

The calculated excitation energies, absorption wavelengths, and oscillator strengths the studied helicenes H1-H14 were calculated at the TD-B3LYP/6-31+G(d) level and those of the studied helicenes H15-H28 were calculated at the TD-B3LYP/6$31+\mathrm{G}(\mathrm{d}) / \mathrm{LANL} 2 \mathrm{DZ}$ level $(6-31+\mathrm{G}(\mathrm{d})$ for $\mathrm{O}, \mathrm{N}, \mathrm{C}$ and $\mathrm{H}$ atoms; LANL2DZ basis set for Se atom).

It is noted that first hyperpolarizability is an important parameter to evaluate the second-order NLO property. In this paper, the second-order NLO response was determined by hyper-Rayleigh scattering ( $\left.\beta_{\mathrm{HRS}}\right)$, as follows: ${ }^{28,29}$

$$
\beta_{\mathrm{HRS}}(0 ; 0,0)=\sqrt{\left\{\beta_{\mathrm{zzz}}^{2}+\beta_{\mathrm{xzz}}^{2}\right\}}
$$

where, $\beta_{\mathrm{zzz}}^{2}$ and $\beta_{\mathrm{xzz}}^{2}$ are the orientational average of the first hyperpolarizability tensor without assuming Kleinman's conditions. Only the static first hyperpolarizability was considered.

The associated depolarization ratio (DR), which gives the shape information of the NLO-phore, reads as follows: ${ }^{30}$

$$
\mathrm{DR}=\frac{\left\langle{\beta_{\mathrm{zzz}}}^{2}\right\rangle}{\left\langle\beta_{\mathrm{ZXx}}{ }^{2}\right\rangle}
$$

$\beta$ is also typically decomposed into the sum of dipolar $(J=1)$ and octupolar $(J=3)$ tensorial components: ${ }^{31}$

$$
\begin{aligned}
& \left\langle\beta_{\mathrm{ZZZ}}{ }^{2}\right\rangle=\frac{9}{45}\left|\beta_{J=1}\right|^{2}+\frac{6}{105}\left|\beta_{J=3}\right|^{3} \\
& \left\langle\beta_{\mathrm{ZXX}}{ }^{2}\right\rangle=\frac{1}{45}\left|\beta_{J=1}\right|^{2}+\frac{4}{105}\left|\beta_{J=3}\right|^{3}
\end{aligned}
$$

The $\beta_{\text {HRS }}$ values $\left(\times 10^{-30}\right.$ esu) of helicenes H1-H14 are calculated by using CAM-B3LYP functionals associated with the $6-31+\mathrm{G}(\mathrm{d})$ basis set and the $\beta_{\text {HRS }}$ values $\left(\times 10^{-30}\right.$ esu $)$ of helicenes H15-H28 are calculated by using CAM-B3LYP associated with the $6-31+\mathrm{G}(\mathrm{d})$ for $\mathrm{O}, \mathrm{N}, \mathrm{C}$ and $\mathrm{H}$ atoms and LANL2DZ basis set for Se atom.

\section{Results and discussion}

\subsection{Molecular structures}

In this paper, twenty-eight expanded helicenes were investigated, as shown in Fig. 1. Their ground state geometrical structures have been fully optimized at B3LYP/6-31G(d) or B3LYP/6-31G(d)/LANL2DZ level. The positive vibrational frequencies confirmed that our studied helicenes are dynamically stable. Helicenes $\mathbf{H 1}$ and $\mathbf{H 1 5}$ has been synthesized and characterized, which possess typical helical structure. ${ }^{23}$ It consists of alternating linearly and angularly fused rings, $\mathrm{H}$ atom at $\mathrm{R}_{1}-\mathrm{R}_{10}$ positions. The X-ray crystal structure unambiguously demonstrated it is helical structures. Taking the helicene H1 as an example to test the feasibility of the selected functional. Several selected geometric structural parameters are compared with the experimental ones (Table S1†), and it is found that the theoretical values are in good agreement with the experimental ones, indicating that our adopted method is suitable to describe the ground state geometrical structure of the studied helicenes.

\subsection{Frontier molecular orbital analysis}

For organic helicenes, their frontier molecular orbitals (FMOs) distributions and energy gaps (HOMO-LUMO gap) are closely related to the electronic and optical properties. The sketch of the HOMO and LUMO orbitals, the calculated HOMO/LUMO energy levels, and energy gaps of helicenes H1-H28 are shown in Fig. 2 and S1. $\dagger$

For helicene H1, its HOMO mainly localizes on rings 4-6, 810 and oxygen atoms, and its LUMO mostly localizes on rings 413, 15 and 16. For helicenes $\mathbf{H 2}$ and H3, their HOMO distributions are almost the same as that of helicene H1, but the LUMO of helicene $\mathbf{H} \mathbf{2}$ primary distributes on the inner rings, and that of helicene $\mathbf{H 3}$ largely distributes on rings 6-13, 15 and 16 , indicating that the introduction of donor $\mathrm{NH}_{2}$ unit at $\mathrm{R}_{1}$ and $R_{2}$ or $R_{3}$ and $R_{4}$ positions has a certain influence on the LUMO distribution of helicene H1. For helicenes H4-H6, their LUMO distributions are nearly the same as that of helicene H1, however, the HOMO distributions of helicenes $\mathbf{H 4}$ and $\mathbf{H 5}$ almost delocalize throughout the inner rings, and that of helicene $\mathbf{H 6}$ mainly localizes on rings 1-6, demonstrating that the introduction of donor $\mathrm{NH}_{2}$ unit at $\mathrm{R}_{5}$ and $\mathrm{R}_{6}, \mathrm{R}_{7}$ and $\mathrm{R}_{8}$ or $\mathrm{R}_{9}$ and $\mathrm{R}_{10}$ positions in helicene $\mathbf{H} \mathbf{1}$ may change the HOMO distribution. For helicenes H7-H11, their HOMO distributions are almost the same as that of helicene H1. However, their LUMO distributions are rather sensitive to the position of $\mathrm{NO}_{2}$ unit. The LUMO distribution of helicene $\mathbf{H 7}$ mainly localizes on rings 8-9 and $\mathrm{NO}_{2}$ unit attached to ring 8, and that of helicene H8 localizes on rings 4-5 and $\mathrm{NO}_{2}$ attached to ring 4, and that of H9 localizes on rings 1-3 and $\mathrm{NO}_{2}$ units, while the LUMO distributions of helicenes $\mathrm{H10}$ and $\mathbf{H 1 1}$ largely localize on rings $1,2,12,13$ and $\mathrm{NO}_{2}$ units. These signify that acceptor $\mathrm{NO}_{2}$ unit at different substituent positions may have remarkably influence on LUMO distribution of helicene H1. For helicene $\mathbf{H 1 2}$ with the donor $\mathrm{NH}_{2}$ unit, its HOMO orbital mainly distributes on rings 5, 6, 8-10 and $\mathrm{O}$ atoms, and its LUMO localizes on rings 4-9, 14 and 15, which indicating that the distributions of HOMO and LUMO partially overlap. The HOMO of helicene $\mathbf{H 1 3}$ locates on rings 4-6, 8-10 and $\mathrm{O}$ atoms attached to rings 5 and 9, while the LUMO distributes on the whole molecule. Compared with helicene H12, the HOMO and LUMO orbitals distributions of helicene $\mathbf{H 1 4}$ are clearly separated. Its HOMO distribution mainly localizes on rings $1,2,4-6$, and $\mathrm{N}$ and $\mathrm{O}$ atoms attached to rings $1-6$, and the LUMO distribution mostly localizes on rings $10-13,16$ and $\mathrm{NO}_{2}$ units attached to rings 1213. The changes of FMO distributions, indicating that the introduction of the electron-withdraw units $\left(\mathrm{NO}_{2}\right)$ facilitates charge separation of frontier molecular orbital, which is beneficial to realize intramolecular charge transfer from HOMO to LUMO. 

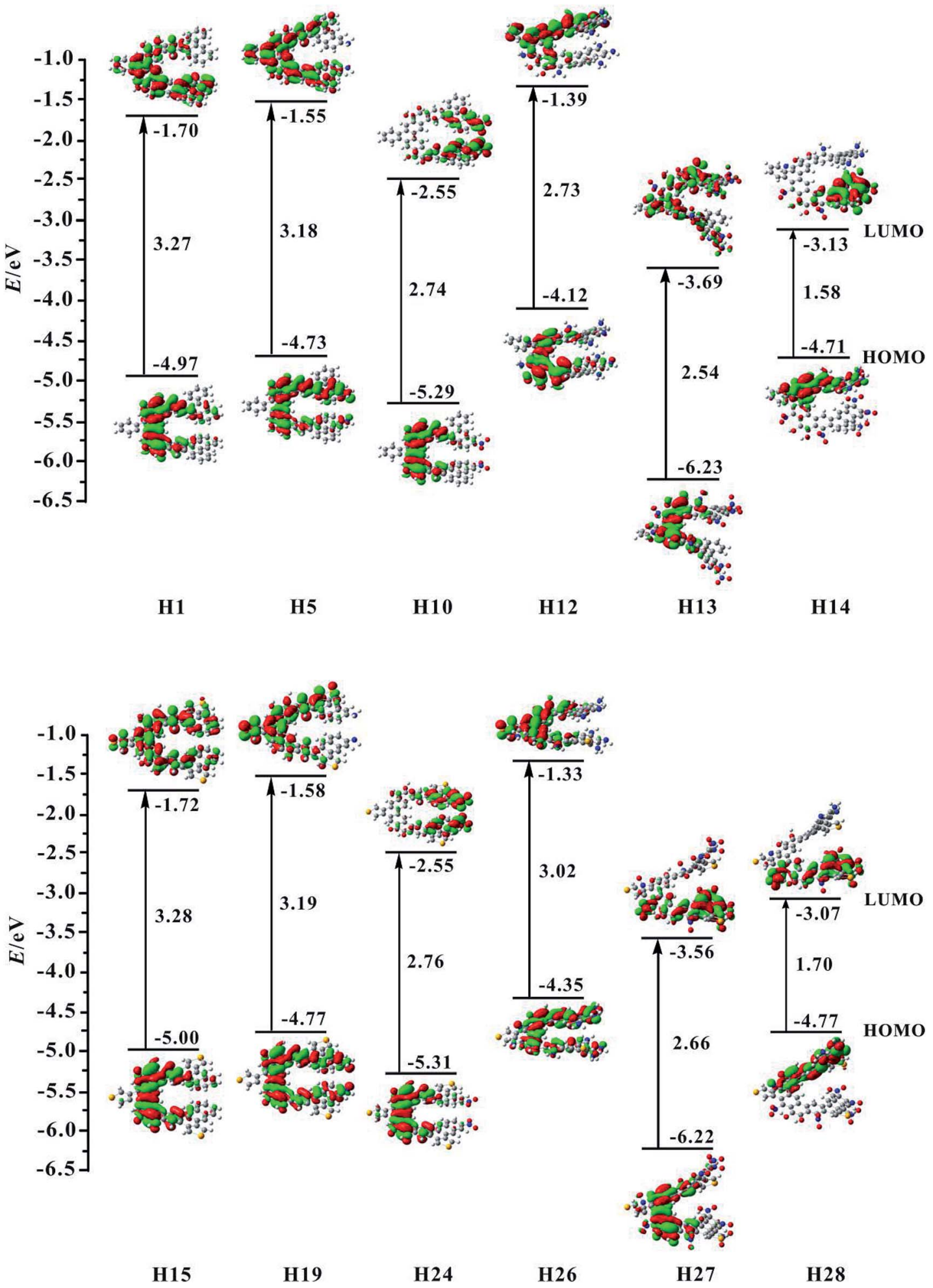

Fig. 2 Contour plots of the HOMO and LUMO for the studied helicenes H1, H5, H10, H12-H15, H19, H24, and H26-H28.

For helicene H15, its HOMO distribution is almost the same as helicene H1. However, its LUMO distribution almost delocalizes over the inner rings and ring 15. For helicene H16, its FMOs are nearly the same as that of helicene H15. The LUMO distributions of helicenes $\mathbf{H 1 7 - H 2 0}$ are almost the same, distributed on rings 4-10 and 15. However, the HOMO distribution of helicene $\mathbf{H 1 7}$ is nearly the same as that of helicene H15, the HOMOs of helicenes H18 and H19 mainly delocalize on inner rings, and the HOMO of helicene $\mathbf{H 2 0}$ mostly localizes on rings 12, 13, 16 and $\mathrm{NH}_{2}$ unit attached to ring 13. By 
observing the FMOs of helicenes H21-H25, it can be concluded that the effect of $\mathrm{NO}_{2}$ unit at different substituent positions on the FMOs of helicene $\mathbf{H 1 5}$ is almost the same as its effect on the FMOs of helicene H1. For helicenes H26-H28, their FMOs distributions have significant changes compared with helicene H15.

Subsequently, we investigate the effect of the different substituents and substituent positions on energy gap. Compared with helicene H1, the HOMO and LUMO energy level of helicenes H2-H6 slightly increase. However, the increase in HOMO energy levels is greater than the increase in LUMO energy levels, so the bands gap of the five substituted helicenes slightly reduce. It is worth mentioning that the band gap of helicene $\mathbf{H 3}$ is the smallest of the five substituted helicenes, so it can be concluded that the band gap of helicene $\mathbf{H 1}$ can be effectively reduced when the $\mathrm{R}_{3}$ and $\mathrm{R}_{4}$ positions are substituted with donor $\mathrm{NH}_{2}$ unit. For helicenes H7-H11, their HOMO and LUMO energy level significantly reduce relative to helicene $\mathbf{H 1}$. However, the LUMO energy level decreases more rapidly than the HOMO energy level, their band gaps are significantly reduced, which is closely related to the introduction of the $\mathrm{NO}_{2}$ unit affects the distribution of LUMO in the above analysis. This indicates that the introduction of acceptor $\mathrm{NO}_{2}$ unit in helicene $\mathbf{H 1}$ can effectively reduce the band gap. In particular, the band gap of helicene $\mathbf{H} 7$ which introduces acceptor $\mathrm{NO}_{2}$ unit at $\mathrm{R}_{\mathbf{1}}$ and $\mathrm{R}_{2}$ positions has been reduced to $2.49 \mathrm{eV}$. For helicene $\mathbf{H 1 2}$, its band gap significantly reduces relative to helicenes $\mathbf{H 1 - H 6}$, indicating that when the $\mathrm{R}_{1}-\mathrm{R}_{10}$ positions are all substituted with donor $\mathrm{NH}_{2}$ unit, the band gap can be effectively reduced. For helicene H13, its band gap also significantly reduced relative to helicene $\mathbf{H 1}$, but does not much change compared to helicenes H7-H11, except that both its HOMO and LUMO energy level greatly reduce. For helicene $\mathbf{H 1 4}$, its band gap is the smallest of helicenes H1-H14, which results from the electronic distributions of HOMO and LUMO are obviously separated. This indicates that the introduction of the combination of donor $\mathrm{NH}_{2}$ and acceptor $\mathrm{NO}_{2}$ unit is an effective method for reducing the band gap of helicene $\mathbf{H 1}$.

For the homologue $\mathbf{H 1 5}$ of helicene H1, the same substituted way was used in helicene H15, which obtained helicenes H16H28. The research found that the HOMO/LUMO energy level and energy gaps of helicenes H15-H28 have the same conclusions as helicenes H1-H14, for example, helicene $\mathbf{H 2 8}$ which is the introduction of acceptor $\mathrm{NO}_{2}$ unit at $\mathrm{R}_{1}, \mathrm{R}_{3}, \mathrm{R}_{5}, \mathrm{R}_{7}$ and $\mathrm{R}_{9}$ positions and donor $\mathrm{NH}_{2}$ unit at $\mathrm{R}_{2}, \mathrm{R}_{4}, \mathrm{R}_{6}, \mathrm{R}_{8}$ and $\mathrm{R}_{10}$ positions, has the smallest energy gap in helicenes $\mathbf{H 1 5}-\mathbf{H 2 8}$. In addition, the electronic structure shows that the visible charge transfer from top (rings 1, 2, 4-6 and $\mathrm{N}$ atoms at $\mathrm{R}_{2}, \mathrm{R}_{4}, \mathrm{R}_{6}$ and $\mathrm{R}_{8}$ positions) to bottom (rings 8-13 and $\mathrm{NO}_{2}$ units at $\mathrm{R}_{1}, \mathrm{R}_{5}$ and $\mathrm{R}_{7}$ positions) of whole molecule. Overall, FMOs and energy gaps of helicenes $\mathbf{H 1}$ and $\mathbf{H 1 5}$ can be effectively tuned through introduction of different substituents at proper positions.

\subsection{Electronic absorption of helicenes H1-H28}

In recent years, the TDDFT method has been widely used in the calculations of electronic transition properties. ${ }^{32-36}$ However, proper selection of the functional and basis set is rather important for accurately describing the electronic transition because each functional or basis set has its own merit. Firstly, four Pople's basis sets (e.g. 6-31G(d), 6-31G(d,p), 6-31+G(d), and $6-311+G(d))$ were selected to evaluate the effect of basis set extension on the electronic absorption wavelength by using B3LYP functional. The calculated main absorption bands of helicene $\mathbf{H 1}$ at the different basis set levels were listed in Table $\mathrm{S} 2 . \dagger$ It is interesting to find that the difference between the absorption wavelengths of the largest basis set and the smallest basis set is about $8 \mathrm{~nm}$. It means that the effect of the basis set size on the calculated absorption wavelength is negligible. Many studies demonstrate that diffuse functions can accurately calculate absorption wavelengths and successfully describe the electronic transition properties. ${ }^{37,38}$ Considering the performance and reasonable computational resource, 6-31+G(d) basis set was selected in the following calculation. Subsequently, the B3LYP, ${ }^{26}$ M06-2X, ${ }^{39,40}$ CAM-B3LYP, ${ }^{41,42}$ and BH\&HLYP ${ }^{43}$ functionals were chosen to test the influence of different functionals on the absorption wavelengths. The results show that the calculated absorption wavelengths of M06-2X, CAM-B3LYP, and BH\&HLYP functionals are similar (Table S3 $\dagger$ ). And, the B3LYP functional slightly underestimates the excitation energy. However, previous studies have shown that the B3LYP functional is the most suitable functional for organic conjugated systems. ${ }^{44-46}$ Thus, the B3LYP functional combined with 6$31+G(d)$ basis set was employed in the following electronic excitation calculations. For the helicenes H15-H28, the LANL2DZ basis set was used for Se atom.

Based on the above results of functional or basis set, the 60 lowest electronic excitation energies of the studied helicenes H1-H14 were calculated at the TD-B3LYP/6-31+G(d) level and those of the studied helicenes $\mathbf{H 1 5}-\mathbf{H 2 8}$ were calculated at the TD-B3LYP/6-31+G(d)/LANL2DZ(6-31+G(d) for O, N, C and $\mathrm{H}$ atoms; LANL2DZ basis set for Se atom) level. The calculated excitation energies, absorption wavelengths, and oscillator strengths are summarized in Table 1 . To better understand the nature of electronic absorption, electron density difference maps (EDDMs) involved into the most intense band were shown in Fig. 3 and $\mathbf{S} 2 . \dagger$

Helicene H1 exhibits one main absorption band with the charge transfer (CT) from rings 4, 5, 12, 13 and 16 to rings 7-11. Helicenes $\mathbf{H} 2$ and $\mathbf{H} 3$ shows three main absorption bands. The most intense absorption band of helicene $\mathbf{H 2}$ is at $313.64 \mathrm{~nm}$, mainly coming from rings $1,2,8-10,12$ and 14 to rings 5-7 charge transfer, while that of helicene $\mathbf{H 3}$ mainly originates from the $\pi \rightarrow \pi^{*}$ character on the entire skeleton. For helicene $\mathbf{H 4}$, there is one main absorption band, the electronic transition is assigned as a CT from rings $2-5,10,12, \mathrm{~N}$ and $\mathrm{O}$ atoms to rings $6-8$ and 16 . With respect to helicene $\mathbf{H 5}$, it is interesting to find that there is a CT from rings $11-13$ and 16 to the other inner rings, besides $\pi \rightarrow \pi^{*}$ character with rings $7-10$. For helicene H6, the absorption band locates at $319.90 \mathrm{~nm}$, with the largest oscillator strength, mainly arises from the $\pi \rightarrow \pi^{*}$ character on the entire skeleton. For helicenes $\mathbf{H 7}$ and $\mathbf{H 8}$, the electronic transition mainly ascribed to the $\pi \rightarrow \pi^{*}$ character on the entire skeleton, while the most intense absorption band 
Table 1 Calculated excitation energies $\left(\Delta E_{\mathrm{ge}}, \mathrm{eV}\right)$, absorption wavelengths $(\lambda, \mathrm{nm})$, and oscillator strengths $(f)$ of the studied helicenes $\mathrm{H} 1$ $\mathrm{H} 28$

\begin{tabular}{|c|c|c|c|c|c|c|c|}
\hline Compound & $\Delta E_{\mathrm{ge}}$ & $\lambda$ & $f$ & Compound & $\Delta E_{\mathrm{ge}}$ & $\lambda$ & $f$ \\
\hline H1 & 3.90 & 318.21 & 0.470 & H15 & 3.71 & 334.41 & 0.911 \\
\hline \multirow[t]{3}{*}{ H2 } & 3.95 & 313.64 & 0.301 & H16 & 4.12 & 300.82 & 0.324 \\
\hline & 3.61 & 343.00 & 0.216 & & 2.99 & 414.39 & 0.172 \\
\hline & 2.58 & 479.76 & 0.156 & & 2.61 & 475.71 & 0.185 \\
\hline \multirow[t]{3}{*}{ H3 } & 4.00 & 310.00 & 0.357 & H17 & 3.94 & 314.99 & 0.161 \\
\hline & 3.54 & 349.96 & 0.286 & & 3.35 & 370.15 & 0.397 \\
\hline & 2.54 & 487.71 & 0.147 & & 2.81 & 440.77 & 0.195 \\
\hline H4 & 3.88 & 319.32 & 0.790 & H18 & 3.65 & 339.48 & 0.621 \\
\hline \multirow[t]{2}{*}{ H5 } & 3.84 & 322.64 & 0.670 & H19 & 3.94 & 314.49 & 0.430 \\
\hline & 3.18 & 389.41 & 0.162 & & & & \\
\hline \multirow[t]{2}{*}{ H6 } & 3.88 & 319.90 & 0.613 & H20 & 3.65 & 339.52 & 0.574 \\
\hline & 3.28 & 378.13 & 0.214 & & & & \\
\hline \multirow[t]{3}{*}{ H7 } & 3.92 & 316.31 & 0.606 & H21 & 3.66 & 338.81 & 0.395 \\
\hline & 3.32 & 373.00 & 0.102 & & 2.72 & 465.57 & 0.135 \\
\hline & 2.75 & 451.32 & 0.175 & & & & \\
\hline \multirow[t]{2}{*}{ H8 } & 3.87 & 320.15 & 0.575 & H22 & 3.72 & 333.53 & 0.529 \\
\hline & 3.53 & 350.82 & 0.118 & & & & \\
\hline H9 & 3.62 & 342.09 & 0.326 & H23 & 3.72 & 333.15 & 0.432 \\
\hline \multirow[t]{2}{*}{ H10 } & 3.68 & 336.69 & 0.560 & H24 & 3.78 & 328.22 & 0.918 \\
\hline & 3.17 & 390.82 & 0.180 & & 2.67 & 464.57 & 0.144 \\
\hline H11 & 3.75 & 330.25 & 0.554 & H25 & 3.67 & 337.52 & 0.508 \\
\hline \multirow[t]{3}{*}{ H12 } & 3.53 & 358.80 & 0.184 & H26 & 3.60 & 344.41 & 0.199 \\
\hline & 2.96 & 419.10 & 0.238 & & 3.13 & 396.23 & 0.248 \\
\hline & 2.50 & 495.16 & 0.100 & & & & \\
\hline \multirow[t]{2}{*}{ H13 } & 3.04 & 407.95 & 0.124 & H27 & 2.99 & 414.98 & 0.096 \\
\hline & 2.08 & 596.13 & 0.121 & & & & \\
\hline \multirow[t]{2}{*}{ H14 } & 2.96 & 418.79 & 0.077 & H28 & 2.99 & 414.11 & 0.093 \\
\hline & 2.68 & 463.13 & 0.096 & & & & \\
\hline
\end{tabular}

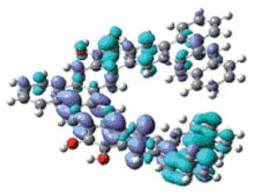

H1-318.21 nm

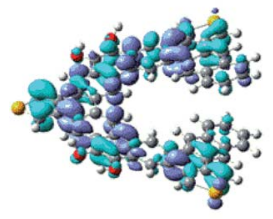

H15-334.41 nm

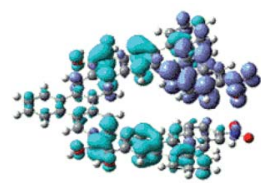

H10-336.69 nm

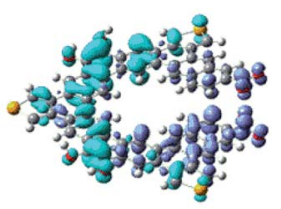

H24-328.22 nm
Fig. 3 Electron density difference maps of helicenes $\mathrm{H} 1, \mathrm{H} 10, \mathrm{H} 15$ and H24. Blue and purple colours indicate depletion and accumulation of electron density, respectively.

of helicene $\mathbf{H 9}$ originates from rings 1, 2, 12, 13 and 16 to the other rings and $\mathrm{NO}_{2}$ unit attached to ring 12 charge transfer, and that of helicene $\mathbf{H 1 0}$ is ascribed to a CT from rings 4, 5, 9, 10, 16 and $O$ atoms attached to rings 5 and 9 to rings 1,2 and $\mathrm{NO}_{2}$ attached to ring 1 , and that of helicene $\mathbf{H 1 1}$ comes from rings 12, 13, 16 and $\mathrm{C}$ atoms connected to $\mathrm{OH}$ units to the other inner rings and $\mathrm{NO}_{2}$ units CT. For helicene H12, it displays three main absorption bands. It is worth mentioning that the oscillator strengths of the second absorption band is largest, this most intense absorption peak at $419.10 \mathrm{~nm}$ attributes from rings $5,6,9,10,12,13, \mathrm{O}$ atoms and $\mathrm{N}$ atoms at $\mathrm{R}_{2}, \mathrm{R}_{3}, \mathrm{R}_{5}-\mathrm{R}_{7}$ positions to the other rings CT. For helicene H13, it has two absorption bands, and its absorption wavelength extended to $596 \mathrm{~nm}$. Its electronic transition arises from rings 8, 10, 15, 16 and $\mathrm{C}$ atoms connected to $\mathrm{OH}$ units to the $\mathrm{NO}_{2}$ units at $\mathrm{R}_{1}, \mathrm{R}_{3}-$ $\mathrm{R}_{5}, \mathrm{R}_{7}, \mathrm{R}_{9}$ and $\mathrm{R}_{10}$ positions CT. For helicene $\mathbf{H 1 4}$, the oscillator strength of the absorption band is very small, less than 0.1 . The most intense absorption band at $463.13 \mathrm{~nm}$ has a charge transfer from rings $1,2,5,6, \mathrm{~N}$ atoms at $\mathrm{R}_{2}, \mathrm{R}_{4}, \mathrm{R}_{6}, \mathrm{R}_{8}, \mathrm{R}_{10}$ positions and $\mathrm{O}$ atoms attached to ring 5 to the other inner rings and $\mathrm{NO}_{2}$ units at $\mathrm{R}_{3}, \mathrm{R}_{5}, \mathrm{R}_{7}, \mathrm{R}_{9}$ positions, and $\pi \rightarrow \pi^{*}$ character on rings 4 and 9.

For helicene H15, it shows one main absorption band, mainly assigned as $\pi \rightarrow \pi^{*}$ character on the entire skeleton. The same as helicene $\mathbf{H 1 5}$, that of helicene $\mathbf{H 1 9}$ also ascribed to the $\pi \rightarrow \pi^{*}$ character on the entire skeleton. Unlike helicene H15, that of helicene $\mathbf{H 1 6}$ comes from rings 12, 13, 15 and 16 to the other rings CT, and that of helicene $\mathbf{H 1 7}$ originates from rings $1,2,11-13,14$ and 16 to the other rings CT, and that of helicene $\mathrm{H18}$ arises from rings 2, 5-9, 14, $\mathrm{O}$ atoms and $\mathrm{N}$ atoms to rings 11-13 and $16 \mathrm{CT}$, and that of helicene $\mathbf{H 2 0}$ attributes from rings 1,2 and the $\mathrm{N}$ atom at $\mathrm{R}_{10}$ position to the other rings CT. For helicene $\mathbf{H 2 1}$, the most intense electronic transition is the same as that of helicene $\mathbf{H 1 5}$. Unlike helicene $\mathbf{H 1 5}$, that of helicene $\mathbf{H 2 2}$ comes from rings 12, 13, 15 and 16 to $\mathrm{NO}_{2}$ units $\mathrm{CT}$, and that of helicene $\mathbf{H 2 3}$ mainly originates from rings 16 to the other rings CT, and that of helicene $\mathbf{H 2 4}$ arises from rings 49 and $14-16$ to rings $10-13$ and $\mathrm{NO}_{2}$ units CT, and that of helicene $\mathbf{H} 25$ attributes from rings 14, 15, C atoms connected to $\mathrm{OH}$ units to the other rings CT. For helicene H26, the second band at $396.23 \mathrm{~nm}$ is the most intense absorption, this absorption has a CT and $\pi \rightarrow \pi^{*}$ character on ring 1-11, 14 and 15. With respect to helicene $\mathbf{H} 27$, the electronic transition originates from rings 4, 5, 9, 14 and $\mathrm{O}$ atoms at rings 5 and 9 to $\mathrm{NO}_{2}$ units at $\mathrm{R}_{5}-\mathrm{R}_{8}$ positions CT, besides the $\pi \rightarrow \pi *$ character within rings 6-8. For helicene $\mathbf{H 2 8}$, the electronic transition mainly arises from rings $1,2,4,14$ and $\mathrm{N}$ atoms attached to rings 1,2 and 4 to the other rings and $\mathrm{NO}_{2}$ units attached to ring 13.

Overall, compared with helicene $\mathbf{H 1}$, the wavelengths of the high-energy absorption band of helicene $\mathbf{H} \mathbf{3}$ are slightly blueshifted, while those of helicenes H2, H4-H6, H7 and H8 remain essentially unchanged. But those of helicenes H9-H11 are red-shifted, and those of helicenes H12-H14 are obviously red shifted $(\Delta \lambda=40 \mathrm{~nm}$ for helicene H12, $\Delta \lambda=89 \mathrm{~nm}$ for helicene $\mathbf{H 1 3}$ and $\Delta \lambda=100 \mathrm{~nm}$ for helicene H14). For helicene H15, its absorption wavelength is $334.41 \mathrm{~nm}$. Compared with helicene H15, the wavelength of the high-energy absorption band of helicenes H16, H17 and H19 are blue-shifted. The absorption wavelengths of helicenes $\mathbf{H 1 8}$ and $\mathbf{H 2 0 - H 2 5}$ are close to helicene H15. The absorption wavelengths of helicenes H26-H28 are obviously red-shifted compared with helicene H15. In general, the electronic transition properties, absorption wavelength and the number of absorption bands of helicenes H1 and H15 can be changed through introduction of different substituents at proper positions. 


\subsection{Second-order NLO properties}

Based on the above analysis, the asymmetric electronic structures of studied helicenes meet the basic requirements for second-order NLO materials. At the same time, the obvious intramolecular CT of these helicenes may result in the large first hyperpolarizability ( $\left.\beta_{\mathrm{HRS}}\right)$. These unique features motivate us to investigate their second-order NLO response.

As we all known, the $\beta_{\text {HRS }}$ is very sensitive to the adopted functionals. Therefore, four popular DFT functionals (i.e. B3LYP, ${ }^{26}$ CAM-B3LYP, ${ }^{41,47}$ M06-2X, ${ }^{39}$ and BH\&HLYP ${ }^{48}$ ) were chosen to strengthen the reliability of our calculation results. The calculated $\beta_{\text {HRS }}$ values of helicenes $\mathbf{H 1 - H 2 8}$ by four different functionals are given in Table S7.† Among the considered functionals, the $\beta_{\mathrm{HRS}}$ value calculated by B3LYP functional is the largest, whereas the $\beta_{\text {HRS }}$ values obtained by other three functionals are relatively close. Previous studies have shown that the long-range corrected functional CAMB3LYP is a reliable method to calculate the $\beta_{\mathrm{HRS}}{ }^{49,50}$ and B3LYP functional overestimates the $\beta_{\mathrm{HRS}}{ }^{51,52}$ Thus, the $\beta_{\mathrm{HRS}}$ values obtained from CAM-B3LYP were used in the following discussion (Table 2).

The calculated $\beta_{\mathrm{HRS}}$ values of our studied helicenes are large. For example, the $\beta_{\mathrm{HRS}}$ value of the helicene $\mathbf{H 2 4}$ is $(29.95 \times$

Table 2 The calculated $\beta_{\text {HRS }}$ values ( $\left.\times 10^{-30} \mathrm{esu}\right)$, depolarization ratios (DRs) and $\left|\beta_{J}\right|$ values $\left(\times 10^{-30}\right.$ esu) of helicenes $\mathrm{H} 1-\mathrm{H} 14$ by using CAMB3LYP functionals associated with the $6-31+G(d)$ basis set and that of helicenes $\mathrm{H} 15-\mathrm{H} 28$ by using CAM-B3LYP functionals associated with the $6-31+G(d)$ for $O, N, C$ and $H$ atoms and LANL2DZ basis set for Se atom

\begin{tabular}{lrrrr}
\hline Compound & $\beta_{\text {HRS }}$ & DR & $\left|\beta_{J=1}\right|$ & $\left|\beta_{J=3}\right|$ \\
\hline H1 & 5.26 & 3.91 & 1045.33 & 1159.44 \\
H2 & 10.57 & 6.56 & 2451.93 & 1301.30 \\
H3 & 4.86 & 2.18 & 635.11 & 1541.19 \\
H4 & 5.02 & 2.83 & 838.51 & 1381.68 \\
H5 & 9.41 & 5.68 & 2111.06 & 1436.33 \\
H6 & 5.59 & 1.71 & 436.40 & 1987.46 \\
H7 & 8.39 & 4.56 & 1764.52 & 1623.98 \\
H8 & 11.04 & 6.05 & 2516.43 & 1543.56 \\
H9 & 9.70 & 5.76 & 2182.60 & 1454.95 \\
H10 & 28.88 & 6.35 & 6650.65 & 3757.64 \\
H11 & 14.11 & 5.78 & 3178.59 & 2104.02 \\
H12 & 10.16 & 3.13 & 1808.64 & 2624.92 \\
H13 & 22.23 & 6.27 & 5106.31 & 2949.23 \\
H14 & 18.21 & 5.31 & 4012.12 & 3018.81 \\
H15 & 5.89 & 3.81 & 1158.22 & 1325.11 \\
H16 & 8.50 & 4.68 & 1790.83 & 1640.37 \\
H17 & 5.79 & 2.57 & 898.50 & 1682.94 \\
H18 & 5.72 & 2.78 & 945.12 & 1588.10 \\
H19 & 10.11 & 5.69 & 2268.77 & 1540.48 \\
H20 & 5.90 & 2.63 & 934.23 & 1692.44 \\
H21 & 7.89 & 3.42 & 1474.83 & 1918.88 \\
H22 & 7.96 & 4.89 & 1712.48 & 1441.10 \\
H23 & 7.82 & 4.79 & 1671.75 & 1445.51 \\
H24 & 29.95 & 6.32 & 6892.77 & 3920.86 \\
H25 & 15.10 & 5.11 & 3290.10 & 2611.43 \\
H26 & 8.30 & 2.88 & 1405.00 & 2255.36 \\
H27 & 26.10 & 5.35 & 5762.05 & 4282.72 \\
H28 & 15.29 & 5.56 & 3410.00 & 2395.30 \\
& & & &
\end{tabular}

$10^{-30} \mathrm{esu}$ ) is about 7 times larger than that of the highly $\pi$ delocalized phenyliminomethyl ferrocene complex. ${ }^{53}$ Thus, our studied helicenes may be the excellent candidates for secondorder NLO materials from the stand point of their large NLO response and intrinsic asymmetric structures. For helicenes $\mathbf{H 3}$, $\mathbf{H 4}$ and H6, their $\beta_{\text {HRS }}$ values are close to the value of helicene H1, which indicates that when the $R_{3}$ and $R_{4}, R_{5}$ and $R_{6}$, or $R_{9}$ and $\mathrm{R}_{10}$ positions are replaced by donor $\mathrm{NH}_{2}$ unit, respectively, their effect on the $\beta_{\text {HRS }}$ value is not significant. For helicenes $\mathbf{H} 2$ and $\mathbf{H 5}$, their $\beta_{\mathrm{HRS}}$ values are about twice that of helicene $\mathbf{H 1}$, which signifies that the introduction of donor $\mathrm{NH}_{2}$ unit at $\mathrm{R}_{1}$ and $R_{2}$ or $R_{7}$ and $R_{8}$ positions can increases the $\beta_{\text {HRS }}$ value. For helicenes $\mathbf{H 7 - H 1 1}$, their $\beta_{\mathrm{HRS}}$ values are larger than helicene H1, which shows that the introduction of acceptor $\mathrm{NO}_{2}$ unit can effective enhance $\beta_{\text {HRS }}$ value. Comparing helicenes H8-H11 and helicenes H3-H6, it is found that the $\beta_{\text {HRS }}$ values of helicene substituted by acceptor $\mathrm{NO}_{2}$ unit is larger than that of helicene substituted by donor $\mathrm{NH}_{2}$ unit at the same substituent position, for example, helicene $\mathbf{H 8}>$ helicene H3. For helicenes H12-H14, their $\beta_{\text {HRS }}$ values are also larger than that of helicene $\mathbf{H 1}$, which manifests that these three substitution methods are also ways to obtain larger $\beta_{\mathrm{HRS}}$ value. In addition, from helicenes $\mathbf{H 1}$ to $\mathbf{H 1 4}$, it can be concluded that the $\beta_{\mathrm{HRS}}$ value of helicene $\mathbf{H 1 0}$ is the largest of all. This indicates that the maximum $\beta_{\mathrm{HRS}}$ value can be obtained by the introduction of acceptor $\mathrm{NO}_{2}$ unit at $\mathrm{R}_{7}$ and $\mathrm{R}_{8}$ positions for helicene $\mathbf{H 1}$, which is attributed to the enhancement of electron acceptor ability. For the homolog H15 of helicene H1, the same substituted way was used in helicene H15, which obtained helicenes H16-H28. It is found that helicenes H15-H28 have the same conclusions as helicenes H1H14, for example, helicene $\mathbf{H 2 4}$ which is the introduction of acceptor $\mathrm{NO}_{2}$ unit at $\mathrm{R}_{7}$ and $\mathrm{R}_{8}$ positions, has the largest $\beta_{\mathrm{HRS}}$ value in helicenes H15-H28. Comparing helicenes H15-H28 with H1-H14, it can be seen that helicenes H15-H28 does not have much improvement in NLO response, for example, the $\beta_{\text {HRS }}$ value of helicene $\mathbf{H 1 0}$ is relatively close to that of helicene H24.

The depolarization ratio (DR) is also an important parameter of the NLO material, which can be used to reveal the contribution of the $\beta_{\text {HRS }}$ response. Specifically, when the DR is larger than 4.26, the dipolar component makes a major contribution. Reversely, the $\beta_{\mathrm{HRS}}$ response is dominantly from octupolar. For our studied helicenes H3, H4, H6, H12, H17, H18, H20, H21 and H26, the octupolar component is dominant. For helicenes $\mathbf{H 2}$, H5, H8-H11, H13, H14, H19, H24, H25, H27 and H28 the dipolar part is larger than the octupolar, which becomes more clearly from dipolar $(J=1)$ and octupolar $(J=3)$ tensorial components. However, for helicenes H1, H7, H15, H16, H22 and $\mathbf{H 2 3}$, the dipolar part is comparable to the octupolar. Thus, the contribution of dipolar $(J=1)$ and octupolar $(J=3)$ components to the NLO response of helicenes H1, H7, H15, H16, $\mathbf{H 2 2}$ and $\mathbf{H 2 3}$ are nearly equal.

To better understand their NLO origins, the corresponding electron density difference maps (EDDMs) of helicenes H1, H10, H15 and H24 were shown in Fig. 3. It can be seen that the NLO origin of helicene $\mathbf{H 1}$ attributes to charger transfer (CT) from rings 4, 5, 12, 13 and 16 to rings $7-11$, and that of helicene 
H15 mainly derives from the localized CT on entire skeleton. Obviously, the CT characters of helicenes $\mathbf{H 1 0}$ and $\mathbf{H 2 4}$ are different from helicenes $\mathbf{H 1}$ and H15. For instance, the NLO origin of helicene $\mathbf{H 1 0}$ mainly because of the obvious CT from rings 4, 5, 9, 10, 16 and $O$ attached rings 5 and 9 to rings 1,2 and $\mathrm{NO}_{2}$ with ring 1 , while that of helicene $\mathbf{H 2 4}$ originates a CT from rings $4-9$ and $14-16$ to rings $10-13$ and the donor $\mathrm{NO}_{2}$ parts.

\section{Conclusions}

In this paper, we employed DFT/TDDFT theory to investigate photophysical properties of twenty-eight benzannulated or selenophene-annulated expanded helicenes. The investigations show that different substituents at different substituent positions have great effects on electronic structure, electronic absorption and the second-order NLO properties. The introduction of the combination of donor and acceptor units can effectively reduce band gap, and the introduction of donor or acceptor unit at $R_{1}-R_{10}$ positions enables a large red shift in the absorption wavelength, and the introduction of a $\mathrm{NO}_{2}$ acceptor unit at $\mathrm{R}_{7}$ and $\mathrm{R}_{8}$ positions may obtain the largest first hyperpolarizability values. All these benzannulated or selenopheneannulated expanded helicenes have large first hyperpolarizability values, indicating that the second-order NLO response can be effectively tuned by the introduction of donor or acceptor units or their combination. In view of large NLO response and intrinsic asymmetric structures, these studied helicenes may become the excellent candidates for secondorder NLO materials, which will further promote the development of high technological applications.

\section{Conflicts of interest}

There are no conflicts to declare.

\section{Acknowledgements}

This work is supported by the Education Department of Jilin Province, China, under Grant number 2016511.

\section{Notes and references}

1 Y. Shen and C. Chen, Chem. Rev., 2012, 112, 1463-1535.

2 M. Richard Henri, Angew. Chem., Int. Ed. Engl., 2003, 13, 649660.

3 J. Katz Thomas, Angew. Chem., Int. Ed., 2000, 39, 1921-1923. 4 A. Urbano, Angew. Chem., Int. Ed., 2003, 42, 3986-3989.

5 M. Daigle, D. Miao, A. Lucotti, M. Tommasini and J. Morin, Angew. Chem., Int. Ed., 2017, 56, 5946.

6 M. Gingras, Chem. Soc. Rev., 2013, 42, 968-1006.

7 M. Gingras, Chem. Soc. Rev., 2013, 42, 1051-1095.

8 T. Fujikawa, Y. Segawa and K. Itami, J. Am. Chem. Soc., 2016, 138, 3587-3595.

9 T. Wohrle, I. Wurzbach, J. Kirres, A. Kostidou, N. Kapernaum, J. Litterscheidt, J. Haenle, P. Staffeld, A. Baro, F. Giesselmann and S. Laschat, Chem. Rev., 2016, 116, 1139-1241.
10 R. Pascal, Chem. Rev., 2006, 106, 4809-4819.

11 S. Choudhary, C. Gozalvez, A. Higelin, I. Krossing, M. MelleFranco and A. Mateo-Alonso, Chem.-Eur. J., 2014, 20, 15251528.

12 S. More, S. Choudhary, A. Higelin, I. Krossing, M. MelleFranco and A. Mateo-Alonso, Chem. Commun., 2014, 50, 1976-1979.

13 D. Cortizo-Lacalle, A. Pertegas, L. Martinez-Sarti, M. MelleFranco, H. Bolink and A. Mateo-Alonso, J. Mater. Chem. C, 2015, 3, 9170-9174.

14 J. Luo, X. Xu, R. Mao and Q. Miao, J. Am. Chem. Soc., 2012, 134, 13796-13803.

15 R. Rieger and K. Müllen, J. Phys. Org. Chem., 2010, 23, 315325.

16 T. Fujikawa, Y. Segawa and K. Itami, J. Org. Chem., 2017, 82, 7745-7749.

17 T. Fujikawa, Y. Segawa and K. Itami, J. Am. Chem. Soc., 2016, 138, 3587-3595.

18 Y. Zhu, Z. Xia, Z. Cai, Z. Yuan, N. Jiang, T. Li, Y. Wang, X. Guo, Z. Li, S. Ma, D. Zhong, Y. Li and J. Wang, J. Am. Chem. Soc., 2018, 140, 4222-4226.

19 T. Hosokawa, Y. Takahashi, T. Matsushima, S. Watanabe, S. Kikkawa, I. Azumaya, A. Tsurusaki and K. Kamikawa, J. Am. Chem. Soc., 2017, 139, 18512-18521.

20 A. Bédard, A. Vlassova, A. C. Hernandez-Perez, A. Bessette, G. S. Hanan, M. A. Heuft and S. K. Collins, Chem.-Eur. J., 2013, 19, 16295-16302.

21 M. Buchta, J. Rybáček, A. Jančařík, A. A. Kudale, M. Buděšínský, J. V. Chocholoušová, J. Vacek, L. Bednárová, I. Císařová and G. J. Bodwell, Chem.-Eur. J., 2015, 21, 8910-8917.

22 N. J. Schuster, D. W. Paley, S. Jockusch, F. Ng, M. L. Steigerwald and C. Nuckolls, Angew. Chem., Int. Ed., 2016, 55, 13519-13523.

23 G. R. Kiel, S. C. Patel, P. W. Smith, D. S. Levine and T. D. Tilley, J. Am. Chem. Soc., 2017, 139, 18456-18459.

24 M. W. Evans and G. Wagnière, Phys. Rev. A, 1990, 42, 67326736.

25 A. D. Becke, Phys. Rev. A, 1988, 38, 3098-3100.

26 A. D. Becke, J. Chem. Phys., 1993, 98, 5648-5652.

27 C. Lee, W. Yang and R. G. Parr, Phys. Rev. B: Condens. Matter Mater. Phys., 1988, 37, 785-789.

28 F. Mançois, L. Sanguinet, J.-L. Pozzo, M. Guillaume, B. Champagne, V. Rodriguez, F. Adamietz, L. Ducasse and F. Castet, J. Phys. Chem. B, 2007, 111, 9795-9802.

29 A. Plaquet, M. Guillaume, B. Champagne, F. Castet, L. Ducasse, J.-L. Pozzo and V. Rodriguez, Phys. Chem. Chem. Phys., 2008, 10, 6223-6232.

30 M. de Wergifosse, J. de Ruyck and B. Champagne, J. Phys. Chem. C, 2014, 118, 8595-8602.

31 P. Beaujean, F. Bondu, A. Plaquet, J. Garcia-Amorós, J. Cusido, F. M. Raymo, F. Castet, V. Rodriguez and B. Champagne, J. Am. Chem. Soc., 2016, 138, 5052-5062.

32 G. Scalmani, M. J. Frisch, B. Mennucci, J. Tomasi, R. Cammi and V. Barone, J. Chem. Phys., 2006, 124, 094107.

33 F. Furche and R. Ahlrichs, J. Chem. Phys., 2004, 121, 1277212773. 
34 C. Liu, Y. Si, S. Shi, G. Yang and X. Pan, Dalton Trans., 2016, 45, 7285-7293.

35 D. Jacquemin, B. Mennucci and C. Adamo, Phys. Chem. Chem. Phys., 2011, 13, 16987-16998.

36 C. Guido, D. Jacquemin, C. Adamo and B. Mennucci, J. Chem. Theory Comput., 2015, 11, 5782-5790.

37 S. Grimme, J. Comput. Chem., 2004, 25, 1463-1473.

38 L. Wang, W.-Y. Wang, Y.-Q. Qiu and H.-Z. Lu, J. Phys. Chem. C, 2015, 119, 24965-24975.

39 J.-L. Chen, J.-T. Hong, K.-J. Wu and W.-P. Hu, Chem. Phys. Lett., 2009, 468, 307-312.

40 E. G. Hohenstein, S. T. Chill and C. D. Sherrill, J. Chem. Theory Comput., 2008, 4, 1996-2000.

41 A. Pedone, J. Chem. Theory Comput., 2013, 9, 4087-4096.

42 A. B. Tathe, L. Rhyman, P. Ramasami and N. Sekar, J. Fluoresc., 2015, 25, 1117-1126.

43 A. Sorkin, M. A. Iron and D. G. Truhlar, J. Chem. Theory Comput., 2008, 4, 307-315.

44 L. Y. Zou, A. M. Ren, J. K. Feng, Y. L. Liu, X. Q. Ran and C. C. Sun, J. Phys. Chem. A, 2008, 112, 12172-12178.
45 Y. He, Y. Huang, J. Li, X. Pang and G. Yang, Org. Electron., 2017, 50, 220-227.

46 C. Liu, Y. Si, X. Pan and G. Yang, RSC Adv., 2015, 5, 7290772915.

47 T. Yanai, D. P. Tew and N. C. Handy, Chem. Phys. Lett., 2004, 393, 51-57.

48 I. H. Nayyar, A. E. Masunov and S. Tretiak, J. Phys. Chem. C, 2013, 117, 18170-18189.

49 M. Torrent-Sucarrat, J. Anglada and J. Luis, J. Chem. Theory Comput., 2011, 7, 3935-3943.

50 M. de Wergifosse and B. Champagne, J. Chem. Phys., 2011, 134, 074113.

51 H. Sun and J. Autschbach, ChemPhysChem, 2013, 14, 24502461.

52 S. J. A. Van Gisbergen, J. G. Snijders and E. J. Baerends, J. Chem. Phys., 1998, 109, 10657-10668.

53 S. K. Pal, A. Krishnan, P. K. Das and A. G. Samuelson, J. Organomet. Chem., 2000, 604, 248-259. 